\title{
Efisiensi Manajemen Modal Kerja Sebelum dan Sesudah Peristiwa Stock Split pada Perusahaan yang Terdaftar di BEI
}

\author{
Dayana Florencia; Bonifatius Junianto Wibowo \\ email : Yunianto@unika.ac.id \\ Program Studi Manajemen, Fakultas Ekonomi dan Bisnis \\ Universitas Katolik Soegijapranata
}

\begin{abstract}
This research was conducted to determine the efficiency of working capital management carried out by companies that do stock splits. The samples used in this research are 11 firms that did stock splits in 2013. Indicators of efficiency are performance index, utilization index and efficiency index. Whereas, paired t test was used to determine the difference in the efficiency of working capital management between before and after the stock split both from the Performance Index, Utilization Index, and Efficiency Index. The results of this study indicate that the company is efficient both before and after the stock split, and there is no difference in the efficiency of working capital management between before and after the stock split. It means that all companies which did stock splits are still able to manage their working capital optimally to create sales. In the future, firms should be able to increase sales more than before so that the efficiency of working capital management becomes higher. Besides, Investors should also invest their money in the company, which has high working capital management efficiency. The reason is that firms with high working capital management efficiency usually generate large profits. For further research, it is better to use a long period of years so that the differences can be known with certainty.

Keywords: efficiency of working capital management, performance index, utilization index, efficiency index, stock split.
\end{abstract}

\section{PENDAHULUAN}

Modal kerja bagi perusahaan sangat penting artinya untuk dipergunakan sebagai modal untuk keperluan kelancaran usaha. Tanpa modal kerja yang memadai, maka dikawatirkan usahanya akan terganggu, disebabkan karena dana yang ada tidak mencukupi untuk membiayai aktivitas operasionalnya. Modal kerja itu sendiri dapat diartikan sebagai investasi yang ditanamkan dalam aset lancar atau aset jangka pendek, seperti kas, bank, surat-surat berharga, piutang, dan persediaan. (Kasmir, 2008). Yang kebutuhannya antara perusahaan satu dengan perusahaan lainnya berbeda, tergantung dari ukuran maupun volume usahanya. 
Namun, kecukupan modal kerjanya harus dijaga supaya aktivitas operasionalnya dapat berjalan lancar. Dengan demkian, perusahaan akan terbebas dari kesulitan keuangan (Munawir, 1988).

Melihat betapa pentingnya modal kerja bagi suatu perusahaan, maka manajemen modal kerja yang tepat perlu diterapkan agar supaya operasional usahanya dapat berjalan lancar. Menurut Muslich (2003), manajamen modal kerja merupakan manajemen aset lancar dan pasiva lancar. Sedangkan, menurut Van Horne dan Wachowics (1997), manajemen modal kerja adalah administrasi aset lancar perusahaan dan pendanaan yang dibutuhkan guna mendukung aset lancar.

Dengan menerapkan manajemen modal kerja yang tepat, berarti efisiensi manajemen modal kerja disuatu perusahaan telah tercapai. Efisiensi manajemen modal kerja dapat dipengaruhi oleh berbagai peristiwa company action, seperti stock split, stock dividend, merger, akuisis, dsbnya

Penelitian sebelumnya mengenai efisiensi manajemen modal kerja pernah dilakukan oleh Gosh dan Maji (2004) pada industri semen di India dengan hasil temuan yang menunjukkan bahwa manajemen modal kerja pada industri tersebut selama ini belum efisien. Temuan itu diperkuat dengan hasil penelitian Kasiran dkk di Malaysia (2015), yang juga menunjukkan bahwa manajemen modal kerja pada usaha kecil dan menengah di Malaysia belum efisien.

Hasil temuan tersebut berbeda dengan hasil temuan Afza dan Nazir (2011) maupun Anandasayanan (2011). Menurut hasil penelitian Afza dan Nazir, manajemen modal kerja pada industri semen di Pakistan sudah efisien. Hal yang sama, dengan hasil penelitian Anandasayanan, yang menunjukkan bahwa manajemen modal kerja pada perusahaan dagang di Srilangka juga efisien.

Dari hasil temuan yang berbeda tersebut, maka perlu dikaji kembali melalui penelitian mengenai efisiensi manajemen modal kerja pada beberapa perusahaan yang telah melakukan stock split pada tahun 2013, dimana pada tahun tersebut banyak perusahaan go public yang melakukan stock split.

Penelitian ini dilakukan untuk mengetahui efisiensi manajemen modal kerja sebelum maupun sesudah stock split yang dilakukan pada sejumlah perusahaan 
pada tahun 2013. Serta untuk mengetahui apakah terdapat perbedaan efisiensi manajemen modal kerja pada perusahaan tersebut antara sebelum dan sesudah stock split.

\section{TINJAUAN PUSTAKA}

\section{Modal Kerja}

Menurut Kasmir (2008), modal kerja diartikan sebagai investasi yang ditanamkan dalam aset lancar atau aset jangka pendek, seperti kas, bank, suratsurat berharga, piutang, persediaan dan aset lancar. Sedangkan menurut Brigham dan Houston (2014) modal kerja atau working capital adalah seluruh aset jangka pendek, saham yang dapat diperjualbelikan, persediaan, dan piutang usaha.

Berdasarkan uraian tersebut, dapatlah diketahui bahwa modal kerja merupakan bagian dari aktiva yang siap untuk dipergunakan dalam pembiayaan operasional usaha.

\section{Manajemen Modal Kerja}

Manajemen modal kerja merupakan manajemen aset lancar dan pasiva lancar. (Muslich, 2003). Sedangkan menurut Van Horne dan Wachowicz (1997), manajemen modal kerja adalah administrasi aset lancar perusahaan dan pendanaan yang dibutuhkan untuk mendukung aset lancar.

Dari penjelasan tersebut, dapat dikemukakan bahwa manajemen modal kerja memiliki arti penting bagi perusahaan. Yaitu, pertama, modal kerja menunjukan ukuran besarnya investasi yang dilakukan perusahaan dalam asetlancar dan klaim atas perusahaan yang diwakili oleh hutang lancar. Kedua, investasi dalam aset likuid, piutang barang adalah sensitif terhadap tingkat produktifitas dan penjualan.

Pengelolaan perusahaan dengan menggunakan manajemen modal kerja yang baik akan memberikan beberapa manfaat, antara lain :

1. Dapat meningkatkan penjualan maupun laba dengn mengoptimalkan penggunaan asset lancar.

2. Terpenuhinya kabutuhan profitibilitas perusahaan.

3. Kebutuhan profitabilitas perusahaan terpenuhi 
4. Kewajiban perusahaan dapat dipenuhi lebih tepat waktu.

5. Kemudahan dalam memperoleh tambahan dana dari kreditur.

6. Melindungi diri jika terjadi krisis modal kerja.

7. Memaksimalkan penggunaan aset lancar untuk meningkatkan penjualan dan laba.

8. Memenuhi kebutuhan profitabilitas perusahaan.

9. Perusahaan mampu memenuhi kewajiban tepat waktu.

10. Memunginkan perusahaan untuk memperoleh tambahan dana dari pada kreditor apabila rasio keungan memenuhi syarat.

11. Melindungi diri apabila terjadi krisis modal kerja akibat turunnya nilai aset lancar.

\section{Efisiensi Manajemen Modal Kerja}

Suatu perusahaan yang berhasil mengelola modal kerjanya dengan baik, maka perusahaan tersebut dapat dikatakan telah menerapkan efisiensi manajemen modal kerjanya dengan tepat. Yang selanjutnya dapat dipastikan tercapainya keseimbangan yang optimal antara profitabilitas dengan resiko (Deloof, 2003). Semakin efisien penggunaan modal kerja, maka akan semakin baik kinerja manajemen perusahaan sehingga kelangsungan jangka panjang perusahaan dapat terjamin.

Menurut Bhattacharya (2007) sebuah perusahaan dikatakan efisien apabila :

1. Penjualan meningkat. Dengan penjualan yang tinggi, maka perusahaan dapat meraih laba yang optimal.

2. Pengeluaran / biaya terkendali. Efisiensi biaya merupakan suatu hal yang penting yang harus dilakukan oleh perusahaan untuk mencapai laba yang optimal.

3. Kenaikan aset lancar (modal kerja) sebanding dengan kenaikan penjualan.

4. Struktur modal berada pada posisi keseimbangan. Struktur modal yang optimal adalah struktur modal yang mengoptimalkan keseimbangan antara risiko dan pengembalian. 
5. Profitabilitas meningkat. Semakin tinggi tingkat profitabilitas menunjukan semakin efektif dan efisien pengelolaan tiap sumber daya perusahaan untuk menghasilkan laba.

Untuk menghitung efisiensi manajemen modal kerja (WCM efficiency) digunakan tiga nilai indeks antara lain performance index, utilization index, dan efficiency index. (Bhattacharya, 2007)

Performance Index (PI wCM) menggambarkan efisiensi penggunaan aset kerja rata-rata dari berbagai komponen aset lancar. Jika kenaikan penjualan lebih tinggi daripada kenaikan aset lancar selama periode tertentu, sebuah perusahaan dapat dikatakan telah mengelola modal kerjanya secara efisien.

Utilization Index (UI WCM) menggambarkan kemampuan perusahaan dalam menggunakan aset lancar secara keseluruhan untuk meningkatkan penjualan. Jika kenaikan total aset lancar digabungkan dengan kenaikan penjualan yang lebih dari proporsional, maka tingkat utilitas aset meningkat sehingga mencerminkan siklus operasi perusahaan.

Efficiency Index (EI wCM) merupakan perkalian performance index dan utilization index. Indeks ini merupakan ukuran efisiensi terakhir dalam manajemen modal kerja dan menggambarkan efisiensi manajemen modal kerja pada perusahaan dalam periode tertentu.

Menghitung indeks kinerja untuk masing-masing komponen aset lancar (kas, piutang, persediaan, dan sebagainya) merupakan perhitungan pertama, kemudian dari masing-masing indeks tersebut dijumlahkan untuk mendapatkan indeks secara keseluruhan yang akan digunakan untuk menghitung PI wCM. Tahap selanjutnya adalah menghitung UI WCM untuk mengetahui sebagaimana penggunaan modal kerja untuk meningkatkan penjualan, dengan cara membagi aset lancar dan penjualan periode tahun sebelumnya dengan tahun berjalan. Tahapan terakhir yaitu menghitung EI wCM dengan mengalikan kedua index sebelumnya yaitu PI wCM dan UI wCM. 
Perusahaan yang efisien memiliki nilai $\geq 1$ pada ketiga indeks tersebut. Dan perusahaan yang memiliki efisiensi manajemen modal kerja adalah perusahaan yang memiliki nilai EI wCM $\geq 1$ (Bhattacharya, 2007).

Penelitian mengenai efisiensi manajemen modal kerja pernah dilakukan oleh Gosh dan Maji (2004) pada industri semen di India dengan sampel 20 perusahaan semen selama tahun 1992 sampai tahun 2002. Hasilnya menunjukkan bahwa dalam kurun waktu enam tahun, sektor industri semen di India memiliki Efficiency Index kurang dari 1, sehingga manajemen modal kerja industri semen di India pada periode tersebut belum efisien.

Hasil temuan tersebut didukung dengan penelitian yang dilakukan oleh Kasiran, Mohamad, dan Chin (2015) pada UKM di Malaysia dengan sampel 24 perusahaan selama tahun 2010 sampai tahun 2013. Yang menunjukkan bahwa manajemen modal kerja dari hampir seluruh UKM yang diteliti juga belum efisien.

Berbeda dengan hasil penelitian manajemen model kerja yang dilakukan oleh beberapa peneliti lain. Menurut hasil penelitian Afza dan Nazir (2011) mengenai manajemen modal kerja pada industri semen di Pakistan dengan sampel 22 perusahaan selama tahun 1989 sampai tahun 2008 menunjukkan bahwa manajemen modal kerja industri semen di negara tersebut ternyata justru efisien. Hal itu diperkuat dengan hasil penelitian yang dilakukan Anandasayanan (2011) pada tujuh perusahaan dagang di Srilangka selama tahun 2004 sampai tahun 2010. Yang menunjukkan apabila secara keseluruhan manajemen modal kerja di perusahaan dagang tersebut efisien.

\section{Kebijakan Stock Split}

Kebijakan Stock Split atau pemecahan saham diartikan sebagai suatu peristiwa pemecahan saham dari satu lembar menjadi beberapa lembar saham (Jogiyanto, 2014). Sedangkan, menurut Van Horne dan Wachowicz (1997), pemecaham saham adalah peningkatan jumlah saham beredar dengan menurunkan nilai nominalnya. Hal yang hampir sama dikemukakan oleh Agus Sartono (2012) 
bahwa pemecahan sama merupakan pemecahan nilai nominal saham menjadi nilai yang lebih kecil.

Menurut Samsul (2006), stock split dikelompokkan kedalam dua jenis (2006), yaitu:

\section{Pemecahan naik (split-up)}

Memecah satu saham menjadi dua atau lebih saham. Artinya nilai nominal saham baru lebih kecil daripada nilai nominal sebelum stock split.

2. Pemecahan turun (split-down atau reverse split)

Gabungan dari beberapa saham menjadi satu saham. Artinya nilai nominal saham baru lebih besar daripada nilai nominal saham sebelum stock split.

Stock Split sering dilakukan karena beberapa alasan tertentu. Menurut Kieso dan Weygandt (2007) terdapat beberapa alasan mengapa suatu perusahaan melakukan stock split, yaitu :

1. Menyesuaikan harga saham pada titik dimana harga tersebut dapat dijangkau oleh pasar.

2. Dengan harga yang dapat dijangkau, stok split memperluas pemegang saham.

3. Memberi kesempatan pada pemegang saham lama untuk mengambil manfaat dari suatu penyesuaian pasar yang tidak sempurna setelah stock split.

\section{Hubungan antara Stock Split dengan Efisiensi Manajemen Modal Kerja}

Harga saham mempengaruhi tingkat permintaan dan penawaran suatu saham. Ketika harga saham perusahaan terlalu tinggi maka permintaan saham akan menurun dan daya beli investor berkurang. Salah satu upaya yang dilakukan perusahaan untuk mengatasi hal tersebut adalah dengan melakukan stock split agar saham bisa dijangkau oleh para calon investor. Secara umum perusahaan yang melakukan stock split adalah perusahaan yang memiliki kinerja baik, yang ditandai dengan tingginya harga saham. (Muharam, 2009 dalam Wijanarko, 2012). Hal tersebut juga disampaikan oleh Jogiyanto (2014) dalam bukunya.

Kinerja perusahan merupakan hasil dari kegiatan operasional perusahaan dengan memanfaatkan modal kerja yang ada dan ditandai dengan pencapaian laba yang 
dihasilkan dari penjualan. Semakin tinggi penjualan yang dihasilkan mengindikasikan kinerja perusahaan yang baik pula. Artinya perusahaan tersebut dapat mengelola modal kerja dengan baik untuk menghasilkan penjualan yang tinggi. Dengan demikian perusahaan yang melakukan stock split adalah perusahaan yang memiliki efisiensi manajemen modal kerja.

\section{Hipotesis Penelitian}

Hipotesis dalam penelitian ini sebagai berikut :

1. Hipotesis 1 (H1) : Terdapat efisiensi manajemen modal kerja sebelum Stock Split.

2. Hipotesis $2(\mathrm{H} 2)$ : Terdapat efisiensi manajemen modal kerja sesudah Stock Split .

3. Hipotesis $3(\mathrm{H} 3)$ : Terdapat perbedaan efisiensi manajemen modal kerja antara sebelum dan sesudah Stock Split.

\section{Kerangka Pemikiran}

Berdasarkan tinjauan pustaka dan penelitian terdahulu maka dapat disusun kerangka pemikiran sebagai berikut :

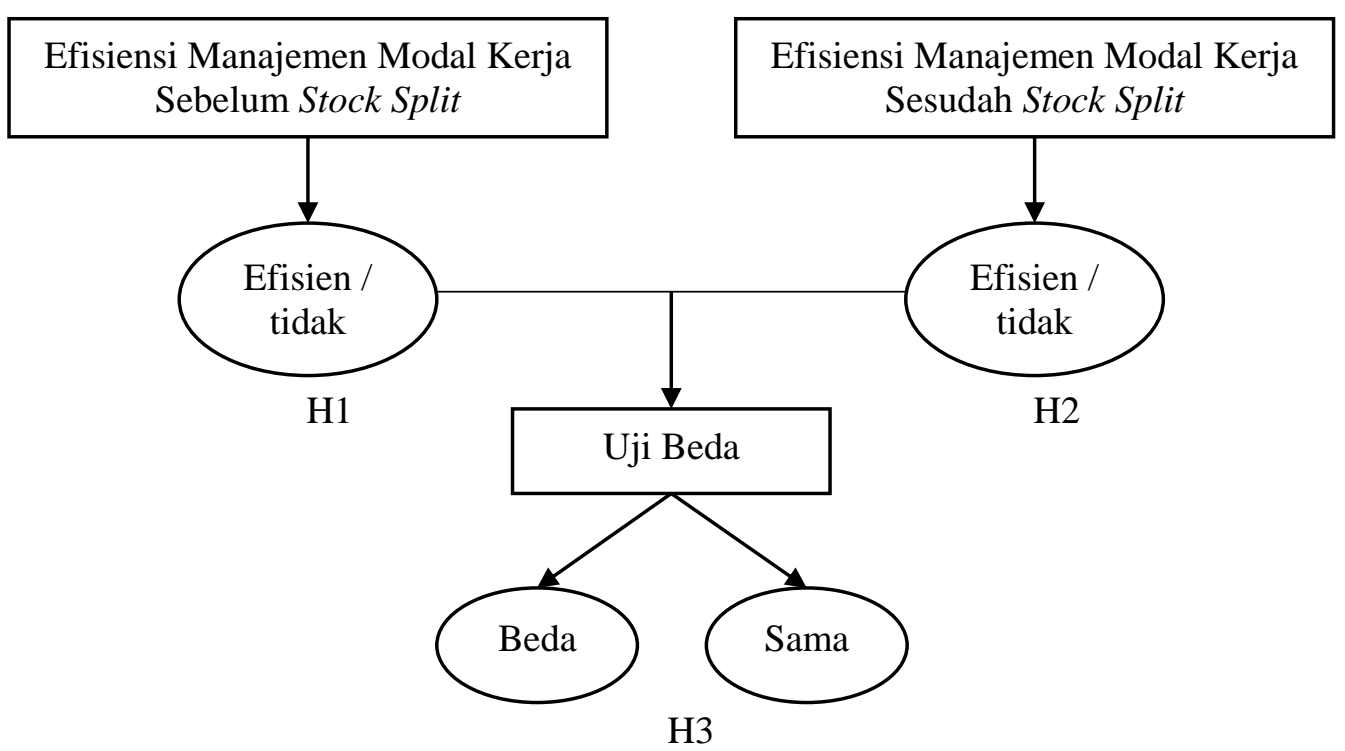

Gambar 1. Kerangka Pikir Penelitian 
Definisi Operasional:

\section{Performance Index (PI $\left.{ }_{W C M}\right)$}

Indeks ini menunjukkan kualitas penggunaan aset kerja dalam aktivitas operasi terutama penjualan. Yang membandingkan kinerja tahun berjalan dengan tahun sebelumnya. Jika indeks ini nilainya $\geq 1$ maka kinerja perusahaan baik.

$$
\mathrm{PI}_{W C M}=\frac{\mathrm{I}_{\mathrm{S}} \sum_{i=1}^{\mathrm{n}} \frac{\mathrm{W}_{\mathrm{i}(\mathrm{t}-\mathrm{l})}}{\mathrm{W}_{\mathrm{it}}}}{\mathrm{N}}
$$

Dimana :

$$
\begin{aligned}
& \text { Is }=\text { sales index }\left(\frac{S_{t}}{S_{t-1}}\right) \\
& W i=\text { individual group of current assets } \\
& N=\text { number of current assets group }
\end{aligned}
$$

\section{Utilization Index (UI $\left.{ }_{W C M}\right)$}

Indeks ini menunjukkan kemampuan perusahaan dalam menggunakan aset lancar secara keseluruhan untuk meningkatkan penjualan. Jika indeks ini nilainya $\geq 1$ maka menunjukkan perusahaan mampu memanfaatkan modal untuk menghasilkan penjualan.

$$
\begin{aligned}
& \mathrm{UI}_{W C M}=\frac{\mathrm{A}_{t-1}}{\mathrm{~A}_{t}} \\
& \text { Dimana : }
\end{aligned}
$$

$$
A=\frac{\text { current assets }}{\text { sales }}
$$

\section{Efficiency Index (EI WCM)}

Indeks ini merupakan ukuran efisiensi terakhir, yang menunjukkan kemampuan perusahaan dalam mengelola modal kerja. Indeks ini diperoleh dengan mengalikan performance index dan utilization index. Jika indeks ini nilainya $\geq 1$ maka menunjukkan efisiensi manajemen modal kerja perusahaan.

$$
\mathrm{EI}{ }_{W C M}=\mathrm{PI}_{\mathrm{WCM}} \times \mathrm{UI}_{\mathrm{WCM}}
$$


JEMAP : Jurnal Ekonomi, Manajemen, Akuntansi dan Perpajakan

\section{METODE PENELITIAN}

Populasi dalam penelitian ini adalah seluruh perusahaan go public yang terdaftar di BEI pada tahun 2013. Sedangkan sampel yang dipilih berdasarkan Purposive Sampling dengan kriteria sebagai berikut :

1. Perusahaan yang melakukan stock split dengan jenis split-up pada tahun 2013.

2. Data tahun 2010-2016 dapat terakses oleh peneliti.

Berdasarkan kriteria diatas didapat sampel penelitian sebanyak 11 perusahaan antara lain (tabel 1):

Tabel 1. Daftar Sampel Perusahaan yang Melakukan Stock Split Tahun 2013

\begin{tabular}{cccc}
\hline No. & $\begin{array}{r}\text { Kode } \\
\text { Saham }\end{array}$ & Nama Emiten & Tanggal \\
\hline 1 & JPFA & Japfa Comfeed Tbk & 19 April 2013 \\
2 & ARNA & Arwana Citramulia Tbk & 2013 Juli 2013 \\
3 & TOWR & Sarana Menara Nusantara Tbk & 29 Juli 2013 \\
4 & AMRT & Sumber Alfaria Trijaya Tbk & 1 Agustus 2013 \\
5 & JRPT & Jaya Real Property Tbk & 28 Agustus 2013 \\
6 & TLKM & Telekomunikasi Indonesia Tbk & 4 September 2013 \\
7 & BATA & Sepatu Bata Tbk & 26 September \\
8 & JKON & Jaya Konstruksi Manggala & 2013 \\
& & Pratama Tbk & \\
9 & MDLN & Moderland Reality Tbk & 13 Nopember 2013 \\
10 & NIPS & Nipress Tbk & 25 Nopember 2013 \\
11 & ROTI & Nippon Indosari Corpindo Tbk & 29 Nopember 2013 \\
\hline
\end{tabular}

Sumber : Data Skunder yang di Olah 2017

Data yang diperlukan berupa data skunder, yaitu data laporan keuangan yang dipublikasikan dari 11 sampel tersebut, yang diperoleh dengan dokumentasi melalui situs resmi BEI (www.idx.co.id). 
Data terkumpul selanjutnya dianalisa dengan menggunakan tehnik analisa kuantitatif, yaitu:

1. Menghitung efisiensi manajemen modal kerja (WCM Efficiency) dengan langkah-langkah sebagai berikut:

a. Menghitung Performance Index (PI wCM). Indeks ini menggambarkan kinerja perusahaan.

b. Menghitung Utilization Index (UI ${ }$ CCM). Indeks ini menggambarkan kemampuan perusahaan memanfaatkan aset lancar untuk menghasilkan penjualan.

c. Menghitung Efficiency Index (EI ${ }_{\text {WCM }}$ ) dengan mengalikan PI ${ }_{W C M}$ dan $U I$ WCM. Indeks ini menunjukkan efisiensi manajemen modal kerja perusahaan.

d. Manajemen modal kerja dikatakan efisien apabila nilai $E I_{W C M} \geq 1$.

\section{Uji Normalitas Data}

Sebelum dilakukan uji t, terlebih dahulu dilakukan uji normalitas data guna melihat apakah data yang ada terdistribusi dengan normal atau tidak. Uji normalitas yang digunakan adalah uji Saphiro-Wilk. Apabila nilai probabilitas (sig) bernilai $\geq 0,05$ maka dapat dikatakan distribusi data normal, namun apabila probabilitas (sig) bernilai $<0,05$ maka dapat dikatakan distribusi data tidak normal.

\section{Paired Sample T Test}

Setelah pengujian normalitas dan dihasilkan distribusi data yang normal, maka dilakukan tahap berikutnya yaitu Paired Sample T Test. Uji Paired Sample T Test digunakan untuk menguji apakah terdapat perbedaan rata-rata dua sampel berhubungan. Kedua sampel berhubungan tersebut antara lain sebelum dan sesudah stock split. Jendela yang digunakan dalam penelitian ini selama tujuh tahun, terdiri atas tiga tahun sebelum perusahaan melakukan stock split, tiga tahun sesudah perusahaan melakukan stock split, dan tahun dimana perusahaan tersebut melakukan stock split. 


\section{HASIL DAN PEMBAHASAN}

\section{Deskripsi Sampel Penelitian.}

Statistik deskriptif Performance Index Working Capital Management (PI WCM) dapat dilihat pada tabel 4.1 dibawah ini

Tabel 2. Statistik Deskriptif PI WCM

\begin{tabular}{cccccc}
\hline \multicolumn{5}{c}{ Descriptive Statistics } \\
\hline & $\mathrm{N}$ & Minimum & Maximum & Mean & $\begin{array}{c}\text { Std. } \\
\text { Deviation }\end{array}$ \\
\hline $\mathbf{t - 3}$ & 11 & .55 & 1.47 & 1.0573 & .28093 \\
$\mathbf{t}-\mathbf{2}$ & 11 & .75 & 3.55 & 1.6118 & 1.00353 \\
$\mathbf{t}-\mathbf{1}$ & 11 & .91 & 2.94 & 1.3036 & .59493 \\
$\mathbf{t = 0}$ & 11 & .71 & 6.55 & 1.4282 & 1.71100 \\
$\mathbf{t + 1}$ & 11 & .69 & 5.04 & 1.9236 & 1.57266 \\
$\mathbf{t + 2}$ & 11 & .76 & 1.59 & 1.0473 & .29021 \\
$\mathbf{t + 3}$ & 11 & .63 & 2.30 & 1.1664 & .52842 \\
\hline Valid N & 11 & & & & \\
(listwise) & & & & & \\
\hline
\end{tabular}

Sumber : Data sekunder yang diolah, 2018

Berdasarkan tabel 2 diatas, nampak bahwa $P I W C M$ pada t-3 memililik nilai minimum 0,55 dan nilai maksimum 1,47. Artinya Performance Index terendah 0,55, yang dimiliki Modernland Realty Tbk dan Performance Index tertinggi 1,47, yang dimiliki Nipress Tbk. Sementara, mean sebesar 1,0573, artinya ratarata industri PI WCM pada t-3 1,0573 dengan standar deviasi sebesar 0,28093.

Kemudian, pada t-2, PI WCM memililik nilai minimum 0,75 dan nilai maksimum 3,55. Artinya Performance Index terendah 0,75, yang dimiliki Telekomunikasi Indonesia Tbk dan Performance Index tertinggi 3,55, yang dimiliki Arwana Citramulia Tbk. Mean yang dihasilkan sebesar 1,6118, artinya rata-rata industri $P I$ WCM pada t-2 1,6118 dengan standar deviasi sebesar 1,00353 
Sedangkan, pada t-1, PI WCM memiliki nilai minimum 0,91 dan nilai maksimum 2,94. Artinya Performance Index terendah 0,91, yang dimiliki Japfa Comfeed Tbk dan Performance Index tertinggi 2,94, yang dimiliki Arwana Citramulia Tbk. Serta mean sebesar 1,3036, artinya rata-rata industri PI WCM pada t-3 1,3036 dengan standar deviasi sebesar 0,59493.

Pada t-0, $\quad$ PI WCM memiliki nilai minimum 0,71 dan nilai maksimum 6,55. Artinya Performance Index terendah 0,71, yang dimiliki Jaya Real Property Tbk dan Performance Index tertinggi 6,55, yang dimiliki Telekomunikasi Indonesia Tbk. Serta mean sebesar 1,4282, artinya rata-rata industri PI WCM pada t-0 1,4282 dengan standar deviasi sebesar 1,71100.

Selanjutnya, pada $\mathrm{t}+1$, PI WCM memiliki nilai minimum 0,69 dan nilai maksimum 5,04. Artinya Performance Index terendah 0,69, yang dimiliki Sarana Menara Nusantara Tbk dan Performance Index tertinggi 5,04, yang dimiliki Nippon Indosari Corpindo Tbk. Dan mean sebesar 1,9236 artinya rata-rata industri $P I$ WCM pada t+1 1,9236 dengan standar deviasi sebesar 1,57266. Kemudian, pada t+2, PI WCM memiliki nilai minimum 0,76 dan nilai maksimum 1,59. Artinya Performance Index terendah 0,76, yang dimiliki Nipress Tbk dan Performance Index tertinggi 1,59, yang dimiliki Arwana Citramulia Tbk. Dan mean sebesar 1,0473 artinya rata-rata industri PI WCM pada $\mathrm{t}+1$ 1,0473 dengan standar deviasi sebesar 0,29021. Sedangkan, pada t+3, PI WCM memiliki nilai minimum 0,63 dan nilai maksimum 2,30. Artinya Performance Index terendah 0,63, yang dimiliki Moderland Realty Tbk dan Performance Index tertinggi 2,30, yang dimiliki Jaya Konstruksi Manggala Pratama Tbk. Serta mean sebesar 1,1664 artinya rata-rata industri $P I W C M$ pada $t+31,1664$ dengan standar deviasi sebesar 0,52842. Statistik deskriptif Utilization Index Working Capital Management (UI WCM) dapat dilihat pada tabel 3 dibawah ini 
Tabel 3. Statistik Deskriptif UI WCM

\begin{tabular}{cccccc}
\hline \multicolumn{5}{c}{ Descriptive Statistics } \\
\hline & $\mathrm{N}$ & Minimum & Maximum & Mean & $\begin{array}{c}\text { Std. } \\
\text { Deviation }\end{array}$ \\
\hline $\mathrm{t}-3$ & 11 & .64 & 1.71 & .9527 & .30611 \\
$\mathrm{t}-2$ & 11 & .91 & 1.49 & 1.1036 & .19826 \\
$\mathrm{t}-1$ & 11 & .81 & 1.27 & .9982 & .15407 \\
$\mathrm{t}=0$ & 11 & .75 & 1.64 & .9900 & .24864 \\
$\mathrm{t}+1$ & 11 & .88 & 1.55 & 1.0864 & .21125 \\
$\mathrm{t}+2$ & 11 & .60 & 1.17 & .8736 & .15622 \\
$\mathrm{t}+3$ & 11 & .66 & 1.14 & .9709 & .13960 \\
\hline Valid N & 11 & & & & \\
(listwise) & & & & & \\
\hline
\end{tabular}

Sumber : Data sekunder yang diolah, 2018

Berdasarkan tabel 3 diatas, nampak bahwa $U I W C M$ pada t-3 memililik nilai minimum 0,64 dan nilai maksimum 1,71. Artinya Utility Index terendah 0,64, yang dimiliki Modernland Realty Tbk dan Utility Index tertinggi 1,71, yang dimiliki Sarana Menara Nusantara Tbk. Dengan mean sebesar 0,9527, artinya rata-rata industri UI WCM pada t-3 0,9527 dengan standar deviasi sebesar 0,30611 .

Kemudian pada t-2, UI WCM memililik nilai minimum 0,91 dan nilai maksimum 1,49. Artinya Utility Index terendah 0,91, yang dimiliki Telekomunikasi Indonesia Tbk dan Utility Index tertinggi 1,49, yang dimiliki Nippon Indosari Corpindo Tbk. Dengan mean sebesar 1,1036, artinya rata-rata industri $U I W C M$ pada t-2 1,1036 dengan standar deviasi sebesar 0,19826.

Selanjutnya, pada t-1, UI WCM memililik nilai minimum 0,81 dan nilai maksimum 1,27. Artinya Utility Index terendah 0,81, yang dimiliki Sumber Alfaria Trijaya Tbk dan Utility Index tertinggi 1,27, yang dimiliki Nippon Indosari Corpindo Tbk. Dengan mean sebesar 0,9982, artinya rata-rata industri UI WCM pada t-1 0,9982 dengan standar deviasi sebesar 0,15407.

Sedangkan, pada t-0, UI WCM memililik nilai minimum 0,75 dan nilai maksimum 1,64. Artinya Utility Index terendah 0,75, yang dimiliki Nippon 
Indosari Corpindo Tbk dan Utility Index tertinggi 1,64, yang dimiliki Moderland Reality Tbk. Dengan mean sebesar 0,9900, artinya rata-rata industri UI WCM pada t-0 0,9900 dengan standar deviasi sebesar 0,24864.

Pada $\mathrm{t}+1$, yaitu setelah Stock Split, UI WCM memililik nilai minimum 0,88 dan nilai maksimum 1,55. Artinya Utility Index terendah 0,88, yang dimiliki Sumber Alfaria Trijaya Tbk dan Utility Index tertinggi 1,55, yang dimiliki Moderland Reality Tbk. Dengan mean sebesar 1,0864, artinya rata-rata industri UI WCM pada t+1 1,0864 dengan standar deviasi sebesar 0,21125.

Kemudian, pada $\mathrm{t}+2$, UI $W C M$ memililik nilai minimum 0,60 dan nilai maksimum 1,17. Artinya Utility Index terendah 0,60, yang dimiliki Nippon Indosari Corpindo Tbk dan Utility Index tertinggi 1,17, yang dimiliki Sumber Alfaria Trijaya Tbk. Dengan mean sebesar 0,8736, artinya rata-rata industri $U I$ WCM pada t+2 0,8736 dengan standar deviasi sebesar 0,15622.

Selanjutnya, pada $\mathrm{t}+3$, UI $W C M$ memililik nilai minimum 0,66 dan nilai maksimum 1,14. Artinya Utility Index terendah 0,66, yang dimiliki Moderland Reality Tbk dan Utility Index tertinggi 1,14, yang dimiliki Telekomunikasi Indonesia Tbk. Dengan mean sebesar 0,9709, artinya rata-rata industri UI WCM pada $\mathrm{t}+3$ 0,9709 dengan standar deviasi sebesar 0,13960.

Statistik deskriptif Efficiency Index Working Capital Management (UI $W C M$ ) dapat dilihat pada tabel 4 dibawah ini

Tabel 4. Statistik Deskriptif EI WCM

\begin{tabular}{cccccc}
\hline \multicolumn{5}{c}{ Descriptive Statistics } \\
\hline & $\mathrm{N}$ & Minimum & Maximum & Mean & $\begin{array}{c}\text { Std. } \\
\text { Deviation }\end{array}$ \\
\hline $\mathrm{t}-3$ & 11 & .35 & 2.26 & 1.0609 & .57747 \\
$\mathrm{t}-2$ & 11 & .69 & 4.51 & 1.7927 & 1.17294 \\
$\mathrm{t}-1$ & 11 & .77 & 2.86 & 1.3027 & .61456 \\
$\mathrm{t}=0$ & 11 & .65 & 5.96 & 1.3591 & 1.54503 \\
$\mathrm{t}+1$ & 11 & .72 & 6.67 & 2.2091 & 2.03855 \\
$\mathrm{t}+2$ & 11 & .67 & 1.27 & .8909 & .21159 \\
$\mathrm{t}+3$ & 11 & .42 & 2.58 & 1.1655 & .61682 \\
\hline Valid N & 11 & & & & \\
(listwise) & & & & & \\
\hline
\end{tabular}

Sumber : Data sekunder yang diolah, 2018 
Berdasarkan tabel 4 diatas, nampak bahwa $E I W C M$ pada t-3 memililik nilai minimum 0,35 dan nilai maksimum 2,26. Artinya Ufficiency Index terendah 0,35, yang dimiliki Modernland Realty Tbk dan Utility Index tertinggi 2,26, yang dimiliki Sarana Menara Nusantara Tbk. Dengan mean sebesar 1,0609, artinya rata-rata industri EI WCM pada t-3 1,0609 dengan standar deviasi sebesar 0,57747 .

Kemudian, pada t-2, EI WCM memililik nilai minimum 0,69 dan nilai maksimum 4,51. Artinya Ufficiency Index terendah 0,69, yang dimiliki Telekomunikasi Indonesia Tbk dan Utility Index tertinggi 4,51, yang dimiliki Arwana Citramulia Tbk. Dengan mean sebesar 1,7927, artinya rata-rata industri EI WCM pada t-2 1,7927 dengan standar deviasi sebesar 1,17294.

Selanjutnya, pada t-1, EI WCM memililik nilai minimum 0,77 dan nilai maksimum 2,86. Artinya Ufficiency Index terendah 0,77, yang dimiliki Telekomunikasi Indonesia Tbk dan Utility Index tertinggi 2,86, yang dimiliki Arwana Citramulia Tbk. Dengan mean sebesar 1,3027, artinya rata-rata industri EI WCM pada t-1 1,3027 dengan standar deviasi sebesar 0,61456.

\section{Efisiensi Manajemen Modal Kerja}

Penilaian efisiensi manajemen modal kerja sebelum Stock Split, baik itu Performance Index, Utilization Index maupun Efficiency Index dapat dilihat pada tabel 5 dibawah.

\section{Tabel 5. Indeks Efisiensi Manajemen Modal Kerja} Sebelum Stock Split

\begin{tabular}{cccccccccc}
\hline & \multicolumn{3}{c}{ PI wcm } & \multicolumn{3}{c}{ UI wcm } & \multicolumn{3}{c}{ EI wcm } \\
& $\mathbf{2 0 1 0}$ & $\mathbf{2 0 1 1}$ & $\mathbf{2 0 1 2}$ & $\mathbf{2 0 1 0}$ & $\mathbf{2 0 1 1}$ & $\mathbf{2 0 1 2}$ & $\mathbf{2 0 1 0}$ & $\mathbf{2 0 1 1}$ & $\mathbf{2 0 1 2}$ \\
\hline JPFA & 0,90 & 1,60 & 0,91 & 0,87 & 1,01 & 0,88 & 0,79 & 1,61 & 0,80 \\
ARNA & 0,93 & 3,55 & 2,94 & 0,80 & 1,27 & 0,97 & 0,75 & 4,51 & 2,86 \\
TOWR & 1,32 & 2,16 & 1,42 & 1,71 & 0,99 & 0,85 & 2,26 & 2,14 & 1,21 \\
AMRT & 1,18 & 1,22 & 1,06 & 0,94 & 1,09 & 0,81 & 1,11 & 1,33 & 0,86 \\
JRPT & 0,72 & 0,80 & 0,92 & 0,80 & 0,96 & 1,20 & 0,58 & 0,77 & 1,11 \\
TLKM & 1,29 & 0,75 & 0,94 & 0,88 & 0,91 & 0,82 & 1,13 & 0,69 & 0,77 \\
BATA & 1,11 & 0,95 & 1,01 & 0,88 & 0,98 & 0,98 & 0,98 & 0,93 & 0,99 \\
JKON & 1,26 & 0,88 & 1,13 & 0,80 & 1,05 & 1,12 & 1,00 & 0,93 & 1,26
\end{tabular}




\begin{tabular}{|c|c|c|c|c|c|c|c|c|c|}
\hline MDLN & 0,55 & 1,38 & 1,63 & 0,64 & 1,42 & 1,03 & 0,35 & 1,96 & 1,67 \\
\hline NIPS & 1,47 & 3,38 & 0,96 & 1,35 & 0,97 & 1,05 & 1,99 & 3,27 & 1,00 \\
\hline ROTI & 0,90 & 1,06 & 1,42 & 0,81 & 1,49 & 1,27 & 0,73 & 1,58 & 1,80 \\
\hline$\overline{\mathbf{x}}$ & 1,06 & 1,61 & 1,30 & $\mathbf{0 , 9 5}$ & 1,10 & 1,00 & 1,06 & 1,79 & 1,30 \\
\hline & & & & & & & \multicolumn{3}{|c|}{$\overline{\mathbf{x}}$ EI wcm $=1,39$} \\
\hline
\end{tabular}

Sumber : Data sekunder yang diolah, 2018

Dari tabel 5 diatas, terlihat bahwa sebelum dilakukan stock split, sebagian besar PI wcm dan UI wcm lebih besar dari 1. Hal itu tentunya telah menyebabkan sebagian besar EI wcm yang dihasilkan dan rata-ratanya per tahun selama tahun 2010 hingga tahun 2012 juga lebih besar dari 1. $(\overline{\mathbf{x}} \mathbf{E I} \mathbf{~ w c m}=\mathbf{1 , 3 9})$

Berdasarkan hasil temuan tersebut, maka manajemen modal kerja sebelum stock split secara keseluruhan sebelum dilakukan kebijakan stock split sudah efisien. Dengan demikian, $\mathbf{H}_{1}$ dalam penelitian ini diterima.

Selanjutnya, setelah dilakukan stock split, penilaian efisiensi manajemen modal kerja sebelum Stock Split, baik itu mengenai Performance Index, Utilization Index maupun Efficiency Index dapat dilihat pada tabel 6 dibawah.

Tabel 6. Indeks Efisiensi Manajemen Modal Kerja Sesudah Stock Split

\begin{tabular}{cccccccccc}
\hline & \multicolumn{3}{c}{ PI wcm } & \multicolumn{3}{c}{ UI wcm } & \multicolumn{3}{c}{ EI wcm } \\
& $\mathbf{2 0 1 4}$ & $\mathbf{2 0 1 5}$ & $\mathbf{2 0 1 6}$ & $\mathbf{2 0 1 4}$ & $\mathbf{2 0 1 5}$ & $\mathbf{2 0 1 6}$ & $\mathbf{2 0 1 4}$ & $\mathbf{2 0 1 5}$ & $\mathbf{2 0 1 6}$ \\
\cline { 1 - 10 } JPFA & 1,32 & 0,94 & 1,07 & 1,18 & 0,93 & 0,94 & 1,56 & 0,87 & 1,01 \\
ARNA & 2,29 & 1,59 & 0,83 & 0,91 & 0,80 & 0,93 & 2,07 & 1,27 & 0,77 \\
TOWR & 0,69 & 0,83 & 0,79 & 1,07 & 0,82 & 1,11 & 0,74 & 0,67 & 0,88 \\
AMRT & 1,01 & 1,08 & 0,86 & 0,88 & 1,17 & 0,88 & 0,88 & 1,26 & 0,76 \\
JRPT & 4,85 & 0,82 & 1,17 & 1,38 & 0,88 & 1,07 & 6,67 & 0,72 & 1,25 \\
TLKM & 1,16 & 1,28 & 1,03 & 1,06 & 0,81 & 1,14 & 1,23 & 1,03 & 1,17 \\
BATA & 1,00 & 0,80 & 1,70 & 0,99 & 0,96 & 0,95 & 0,99 & 0,77 & 1,61 \\
JKON & 0,75 & 0,83 & 2,30 & 0,97 & 1,02 & 1,12 & 0,72 & 0,85 & 2,58 \\
MDLN & 2,01 & 1,11 & 0,63 & 1,55 & 0,69 & 0,66 & 3,11 & 0,76 & 0,42 \\
NIPS & 1,04 & 0,76 & 0,70 & 0,89 & 0,93 & 0,89 & 0,93 & 0,70 & 0,63 \\
ROTI & 5,04 & 1,48 & $-1,75$ & 1,07 & 0,60 & 0,99 & 5,40 & 0,90 & 1,74 \\
\hline$\overline{\mathbf{x}}$ & $\mathbf{1 , 9 2}$ & $\mathbf{1 , 0 5}$ & $\mathbf{1 , 1 7}$ & $\mathbf{1 , 0 9}$ & $\mathbf{0 , 8 7}$ & $\mathbf{0 , 9 7}$ & $\mathbf{2 , 2 1}$ & $\mathbf{0 , 8 9}$ & $\mathbf{1 , 1 7}$ \\
& & & & & & & $\overline{\mathbf{x}}=$ & $\mathbf{1 , 4 2}$ & \\
\hline
\end{tabular}

Sumber : Data sekunder yang diolah, 2018 
Dari tabel 6 diatas, terlihat bahwa setelah dilakukan kebijakan stock split, sebagian besar PI wcm dan UI wcm masih lebih besar dari 1. Kondisi itu, tentunya telah menghasilkan EI wcm yang sebagian besar lebih besar dari 1 . Demikian juga, rata-rata EI wcm setelah kebijakan stock split lebih besar dari $1(\overline{\boldsymbol{x}}$ $\boldsymbol{E} \boldsymbol{I} \boldsymbol{w c m}=\mathbf{1 , 4 2}$ ). Hal itu menunjukkan apabila manajemen modal kerja sesudah dilakukan kebijakan stock split masih tetap efisien. Dengan demikian, H2 dalam penelitian ini diterima.

Sebelum dilakukan uji beda efisiensi manajemen modal kerja melalui uji t, terlebih dahulu dilakukan uji normalitas data. Dengan menggunakan uji SaphiroWilk, diperoleh PI wcm sebelum stock split 0,860>0,05 dan sesudah stock split 0,244>0,05, UI wcm sebelum stock split 0,637>0,05 dan sesudah stock split 0,900>0,05, serta EI wcm sebelum stock split 0,627>0,05 dan sesudah stock split $0,387>0,05$. Oleh karena, hasil pengujian menunjukkan tingkat signifikansinya lebih besar dari 0,05, baik sebelum maupun sesudah dilakukan kebijakan stock split, maka data variabel PI wcm, UI wcm maupun EI wcm berdistribusi normal.

Selanjutnya, dengan menggunakan Paired Sample T Test, diperoleh t hitung lebih kecil dari t tabel $(0,062<2,086)$. Oleh karena $t$ hitung $(0,062)$ berada di daerah penerimaan Ho, maka tidak terdapat perbedaan signifikan efisiensi manajemen modal kerja antara sebelum maupun sesudah dilakukan stock split. Dengan demikian, $\mathbf{H}_{3}$ dalam penelitian ini ditolak.

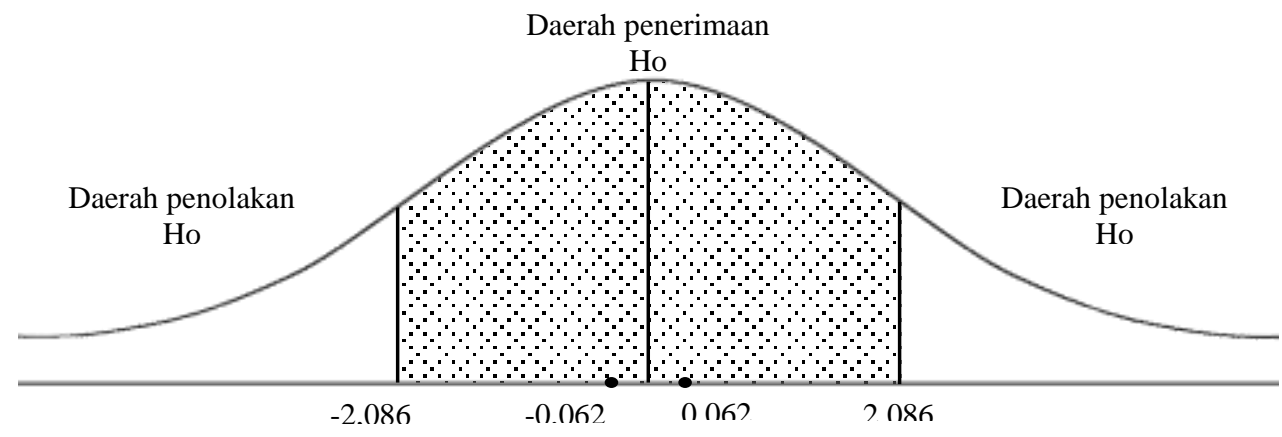

Gambar 1.1. Uji Hipotesis Komparatif Dua Pihak

Sumber : Data sekunder yang di diolah, 2018 
Hasil penelitian tersebut mendukung penelitian yang pernah dilakukan Afza dan Nazir (2011) maupun Anandasayanan (2011). Yang masing-masing menunjukkan adanya efisiensi manajemen modal kerja di Pakistan dan di Srilanka.

Manajemen modal kerja yang efisien terjadi karena dana yang tersedia untuk memenuhi kebutuhan modal kerja perusahaan telah dikelola dengan optimal, tanpa ada yang menganggur, baik itu sebelum maupun sesudah dilakukan kebijakan stock split.

Dengan kebijakan stock split, peningkatan modal saham akibat kenaikan penjualan saham telah dipergunakan sepenuhnya untuk membiayai peningkatan penjualan. Hal itu menandakan bahwa manajemen modal kerja perusahaan tetap efisien.

\section{SIMPULAN DAN SARAN}

Dari hasil pengujian dan pembahasan diatas, dapatlah dikemukakan bahwa perusahaan memiliki kemampuan dalam mengelola modal kerjanya berapapun besarnya. Artinya, perusahaan masih dapat mengoptimalkan modal kerja yang dimiliki untuk menghasilkan penjualan tertentu, terutama sesudah perusahaan melakukan stock split.

Menilik dari tidak adanya perbedaan efisieni dalam pengelolaan modal kerja, maka dapat dikatakan apabila kemampuan perusahaan dalam menghasilkan penjualan dengan modal kerja yang ada tetap sama.

Berkaitan dengan hal itu, maka untuk kedepannya hendaknya penjualan lebih ditingkatkan agar supaya efisiensi manajemen modal kerja dapat lebih tinggi.

Bagi investor sebaiknya berinvestasi pada perusahaan yang efisiensi modal kerjanya tinggi. Alasannya adalah pada perusahaan yang efisiensi modal kerjanya tinggi selalu menghasilkan laba yang tinggi. Sehingga hal itu menyebabkan dividen yang dibagikan meningkat. 
Untuk penelitian lebih lanjut hendaknya menggunakan jendela pengamatan lebih panjang agar dapat diketahui dengan pasti ada atau tidaknya perbedaan.

\section{Referensi}

Afza, T., \& Nazir, M. S. (2011). Working Capital Management Efficiency of Cement Sector of Pakistan, 2(5), 223-235. Diunduh dari https://www.researchgate.net/profile/Talat_Afza/publication/233842286_W orking_Capital_Management_Efficiency_of_Cement_Sector_of_Pakistan/li nks/0fcfd50c0707de05f1000000/Working-Capital-Management-Efficiencyof-Cement-Sector-of-Pakistan.pdf

Anandasayanan, S. (2011). A Comparative study on Working Capital Management efficiency of Listed Trading Companies In Sri Lanka, 1-9. http://dx.doi.org/10.2139/ssrn.2385962

Bhattacharya, H. (2007). Total Management by Ratios (2nd ed.). New Delhi: Sage Publication India Pvt Ltd.

Brigham, E. F., \& Houston, J. F. (2014). Dasar-Dasar Manajemen Keuangan (Edisi 11 B). Jakarta: Salemba Empat.

Copeland, T. E. (1979). Liquidity Changes Following Stock Splits. The Journal of Finance, 34(1), 115-141. Diunduh dari http://www.sef.hku.hk/ wsuen/teaching/year2/liquidity.pdf

Deloof, M. (2003). Does Working Capital Management Affect Profitability of Belgian Firms?, 30(3) \& (4), 573-587. Diunduh dari https://repository.uantwerpen.be/docman/irua/d22bc3/36276.pdf

Gosh, S. K., \& Maji, S. G. (2004). Working capital management efficiency : A study on the Indian cement industry. Diunduh dari https://www.researchgate.net/profile/Santi_Maji/publication/303880208_W orking_capital_management_efficiency_A_study_on_the_Indian_cement_in dustry/links/575a4a4208ae9a9c954f2e84.pdf

Jogiyanto. (2014). Teori Portofolio dan Analisis Investasi (Edisi kesepuluh). Yogyakarta: BPFE.

Kasiran, F. W., Mohammad, N. A., \& Chin, O. (2015). Working Capital Management Efficiency: A Study on the Small Medium Enterprise in Malaysia, 35, 297-303. https://doi.org/10.1016/S2212-5671(16)00037-X

Kasmir. (2008). Analisa Laporan Keuangan. Jakarta: PT Bumi Aksara.

Kieso, D. E., Wegandt, J. J., \& Warfield, T. D. (2007). Akuntansi Intermediate Jilid 2 (Edisi 12). Jakarta: Erlangga.

Munawir, S. (1988). Analisa Laporan Keuangan (Edisi ketiga). Yogyakarta: Liberty. 
JEMAP : Jurnal Ekonomi, Manajemen, Akuntansi dan Perpajakan

Muslich, M. (2003). Manajemen Keuangan Modern: Analisis, Perencanaan, dan Kebijaksanaan. Jakarta: PT Bumi Aksara.

Samsul, M. (2006). Pasar Modal dan Manajemen Portofolio. Jakarta: Erlangga.

Sartono, A. (2012). Manajemen Keuangan Teori dan Apikasi (Edisi keempat). Yogyakarta: BPFE.

Sugiyono, P. D. (2010). Statistika Untuk Penelitian. Bandung: Alfabeta.

Van Horne, J. C., \& Wachowicz, J. M. (1997). Prinsip-Prinsip Manajemen

Keuangan (Edisi Indonesia). Jakarta: Salemba Empat.

Wijanarko, I. (2012). Analisis Pengaruh Pemecahan Saham ( Stock Split)

Terhadap Likuiditas Saham Dan Return Saham. (Skripsi S1, Universitas

Diponegoro). Diunduh dari

http://eprints.undip.ac.id/36139/1/WIJANARKO.pdf

www.idx.co.id 